\title{
ESTUDO COMPARATIVO ENTRE A SECAGEM DE GRÃOS DE GIRASSOL EM LEITO FIXO E EM LEITO DE JORRO
}

\author{
A. A. EVANGELISTA NETO ${ }^{1,2}$, W. M. ARAÚJO ${ }^{2}$, O. L. S. ALSINA ${ }^{3}$, M. F. D. MEDEIROS² \\ ${ }^{1}$ Instituto Federal de Educação, Ciência e Tecnologia do Rio Grande do Norte - IFRN Campus Apodi \\ ${ }^{2}$ Universidade Federal do Rio Grande do Norte - UFRN, Departamento de Engenharia Química \\ ${ }^{3}$ Universidade Tiradentes - UNIT \\ E-mail para contato: alcivan.almeida@ifrn.edu.br
}

\begin{abstract}
RESUMO - Neste trabalho foram estudados dois métodos de secagem para os grãos de girassol recém-colhidos, em leito fixo utilizando estufa com circulação de ar e em leito de jorro, ambos a temperatura de $70{ }^{\circ} \mathrm{C}$. Para o leito fixo, foram secos $360 \mathrm{~g}$ de grãos distribuídos em bandeja perfurada, com espessura de $2 \mathrm{~cm}$. Já para o leito de jorro, as cargas de grãos processadas foram de 1500 e 2500 g. Comparativamente ao leito fixo, a secagem no jorro foi mais eficiente. Obtiveram-se as curvas de secagem para os dois procedimentos sendo ajustados os modelos de FICK e PAGE aos dados experimentais. Os modelos representaram muito bem a secagem dos grãos tanto na estufa como no leito de jorro. Foram obtidas as curvas de equilíbrio higroscópico na temperatura ambiente dos grãos secos na estufa e no leito de jorro. O modelo de GAB representou muito bem os dados de equilíbrio, observando-se que houve influência do tipo de secagem nas características higroscópicas dos grãos.
\end{abstract}

\section{INTRODUÇÃO}

O girassol é considerado um alimento funcional (Pesagro, 2007 apud Santos, 2009) e seu óleo pode ser utilizado como matéria-prima para a produção de biocombustíveis. A torta, subproduto da extração, contém quantidade satisfatória de proteínas, em torno de $25 \%$, própria para a utilização como ração animal (Santos, 2009). Considerando que as técnicas empregadas no beneficiamento e armazenamento dos grãos devem assegurar suas características físicas, químicas e fisiológicas, este trabalho trata dos estudos iniciais sobre as condições de secagem que venham a favorecer o armazenamento e a qualidade fisiológica das sementes de girassol. Foi realizado um estudo comparativo entre a secagem destes grãos em estufa com circulação de ar (leito fixo) e em leito de jorro, para uma temperatura de $70{ }^{\circ} \mathrm{C}$ sendo obtidas as curvas de secagem e de equilíbrio higroscópico na temperatura ambiente para os grãos processados em ambos os equipamentos.

\section{FUNDAMENTAÇÃO TEÓRICA}

O girassol é uma dicotiledônea da família Compositae, com sistema radicular do tipo pivotante, 


\section{9 a 22 de outubro de 2014 \\ Florianópolis/SC}

ou seja, possui uma raiz principal vigorosa que cresce aprofundando-se no solo (Santos, 2009). Seu cultivo se adequa a muitos tipos de clima, sendo, portanto, um tipo de cultura bem apropriada para o Brasil.

Os grãos geralmente são colhidos com um alto teor de umidade, a fim de se obter maiores rendimentos, minimizando as perdas causadas pelo ataque de pássaros e por danos mecânicos (GINER e GELY, 2005). A escolha do método da secagem apropriado é muito importante para manutenção das propriedades das sementes, seja para replantio, armazenamento ou extração do óleo.

Apesar de uma grande quantidade de técnicas serem utilizadas atualmente para a secagem de sementes, o processo mais empregado é a secagem natural realizada ao ar livre (RANGANNA et al., 2002). A crescente necessidade de se obter produtos de alta qualidade a um custo competitivo tem levado à investigação experimental de vários métodos de secagem artificial (SANTOS, 2009).

Dentre os secadores convectivos empregados na secagem de grãos como arroz, feijão, lentilha etc. encontra-se o secador de leito de jorro, equipamento que tem por finalidade promover íntimo contato entre um fluido e partículas relativamente grandes que apresentam fluidização de baixa qualidade. Foi desenvolvido por Mathur e Gishler em 1955 com a primeira unidade industrial implantada no Canadá em 1963 para secagem de ervilha, lentilha e semente de milho (Epstein e Grace, 2011). A técnica de secagem em leito de jorro é aplicada com eficiência à secagem de materiais granulares, pastas e suspensões, à granulação e ao recobrimento de partículas (Epstein e Grace, 2011).

\section{MATERIAIS E MÉTODOS}

\subsection{Materiais}

Os grãos de girassol foram cultivados e colhidos na área destinada a plantio do IFRN - Campus Apodi, com um teor de umidade de 35\% em média (base úmida). Logo após a colheita, os grãos foram acondicionados em recipiente hermeticamente fechado e conduzidos ao laboratório para processamento. Os grãos foram caracterizados quanto ao tamanho, densidade e esfericidade.

\subsection{Métodos}

Secagem em estufa com circulação de ar (leito fixo): Foi utilizada estufa com circulação forçada de ar, da marca Tecnal, do tipo TE-394/L, com controle de temperatura do ar. Os experimentos foram conduzidos em cestas de metal no formato de bandejas circulares com malha de $3 \mathrm{~mm}$. Foram utilizadas 3 bandejas carregadas com cerca de $120 \mathrm{~g}$ de sementes distribuídas em camada fina de $2 \mathrm{~cm}$ de espessura. A temperatura foi controlada para $70{ }^{\circ} \mathrm{C}$, realizando-se acompanhamento da perda de massa e atividade de água das sementes ao longo da secagem. A atividade de água foi medida utilizando-se um analisador de atividade de água (Aqualab).

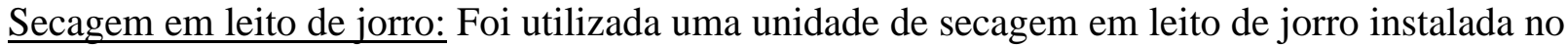
Laboratório de Secagem e Sistemas Particulados da UFRN, equipada com toda a instrumentação 
necessária para medidas das variáveis de processo e controle da temperatura do ar de secagem. O secador consiste de um leito de jorro cônico-cilíndrico, construído em aço inoxidável com visores em acrílico. A base cônica, com ângulo incluso de $60^{\circ}$, tem altura de $0,13 \mathrm{~m}$ e diâmetro de entrada de 0,03 m. A coluna cilíndrica tem $0,18 \mathrm{~m}$ de diâmetro e altura de $0,72 \mathrm{~m}$. O ciclone, do tipo Lapple, com 0,10 $\mathrm{m}$ de diâmetro de coluna, promove a separação e o recolhimento do pó proveniente do atrito dos grãos. Foi utilizado um soprador da marca IBRAM-Weq modelo CR- $6 \mathrm{com} 6 \mathrm{cv}$ de potência e um aquecedor elétrico composto de um conjunto de duas resistências, com potência total de $2.000 \mathrm{~W}$, suficiente para manter as condições de aquecimento nos experimentos propostos. Duas cargas de grãos foram processadas para uma temperatura de operação de $70^{\circ} \mathrm{C}$ : 1500 e $2500 \mathrm{~g}$. Pequenas amostras eram retiradas em um intervalo de 10 minutos, parar acompanhar a perda de umidade e de atividade de água das ementes.

Curvas de Equilíbrio Higroscópico: Os dados de umidade em base seca, obtidos a partir da pesagem do material, foram correlacionados com os dados de atividade de água, obtendo-se as isotermas de equilíbrio higroscópico na temperatura de $25^{\circ} \mathrm{C}$, que corresponde à temperatura em que foram realizadas as medidas da atividade de água no analisador de atividade.

Modelagem: A partir dos dados de umidade em base seca em função do tempo, foram obtidas as curvas da razão de umidade em função do tempo. A partir da análise das curvas, foram ajustados aos dados experimentais modelos de secagem aplicados aos processos transientes: o modelo de PAGE, representado pela Equação 1, e o modelo difusional baseado na segunda lei de FICK truncado no $5^{\circ}$ termo da série, representado pela Equação 2:

$$
\begin{aligned}
& M=\frac{U_{b s}-\mathrm{U}_{\mathrm{eq}}}{\mathrm{U}_{\mathrm{bsi}}-\mathrm{U}_{\mathrm{eq}}}=e^{-k t^{n}} \\
& M=\frac{U_{b s}-\mathrm{U}_{\mathrm{eq}}}{\mathrm{U}_{\mathrm{bsi}}-\mathrm{U}_{\mathrm{eq}}}=\frac{8}{\pi^{2}} \sum_{\mathrm{n}=0}^{\infty} \frac{1}{(2 \mathrm{n}+1)^{2}} \exp \left(-(2 \mathrm{n}+1)^{2} \frac{\pi^{2} \mathrm{D}_{\mathrm{eff}} \mathrm{t}}{4 \mathrm{j}^{2}}\right)
\end{aligned}
$$

Com os dados de umidade em função da atividade de água dos grãos no processo de dessorção, foram construídas as curvas de equilíbrio higroscópico. Para representar as isotermas, foram ajustados aos dados experimentais o modelo de GAB, representado pela Equação 3:

$$
U b s=\frac{X_{m} C_{g} K a_{w}}{\left(1-K a_{w}\right)\left(1+\left(C_{g}-1\right) K a_{w}\right)}
$$

\section{RESULTADOS E DISCUSSÕES}

Na Tabela 1 são apresentados os resultados referentes à caracterização dos grãos: 
Tabela 1 - Caracterização dos Grãos

\begin{tabular}{c|c|c|c|c|c|c|c|c|c|c|c}
\hline \multicolumn{10}{c}{ Dimensões e Desvios } \\
\hline $\begin{array}{c}\mathrm{L} \\
(\mathrm{mm})\end{array}$ & $\sigma$ & $\begin{array}{c}\mathrm{W} \\
(\mathrm{mm})\end{array}$ & $\sigma$ & $\begin{array}{c}\mathrm{E} \\
(\mathrm{mm})\end{array}$ & $\sigma$ & $\begin{array}{c}\text { De } \\
(\mathrm{mm})\end{array}$ & $\sigma$ & $\begin{array}{c}\rho_{\mathrm{p}} \\
\left(\mathrm{g} / \mathrm{cm}^{3}\right)\end{array}$ & $\sigma$ & $\Phi$ & $\sigma$ \\
\hline 10,6 & 0,40 & 4,55 & 0,19 & 3,13 & 0,20 & 5,32 & 0,17 & 0,739 & 0,023 & 0,50 & 0,02 \\
\hline
\end{tabular}

O diâmetro equivalente de cada grão foi calculado, a partir das dimensões medidas com paquímetro (comprimento (L), largura (W) e espessura (E)), utilizando a equação proposta por Mohsenin (1980):

$$
\mathrm{D}_{\mathrm{e}}=(\mathrm{LWE})^{1 / 3}
$$

Na Figura 1, pode-se analisar o efeito da carga de grãos sobre as curvas de secagem para os dois equipamentos. Mesmo com cargas bem superiores, as curvas para o leito de jorro mostram uma queda mais rápida na umidade quando comparada à secagem na estufa. Para atingir uma umidade de $6,2 \%$ foram necessários 75 e 80 minutos de secagem no leito de jorro para as cargas de 1500 e $2500 \mathrm{~g}$, respectivamente. Para atingir o mesmo nível de umidade, $360 \mathrm{~g}$ de grãos foram secados na estufa por 254 minutos. Estes resultados eram esperados e são justificados pela diferença entre as áreas específicas de secagem, $17,12 \mathrm{~cm}^{2} / \mathrm{g}$ para os grãos processados no leito de jorro e $2,94 \mathrm{~cm}^{2} / \mathrm{g}$ para a secagem dos grãos em camada fina na estufa com escoamento paralelo do ar sobre as duas faces. Para o leito de jorro, a área de secagem é considerada a soma das áreas superficiais de todos os grãos. Para o leito fixo com escoamento paralelo de ar, a área de secagem corresponde à área das duas faces em contato com o ar. Destaca-se, assim, a maior eficiência na secagem dos grãos no leito de jorro, quando se considera o curto tempo de secagem para atingir um baixo teor de umidade. Todavia, evidencia-se a importância de se avaliar em trabalhos futuros o consumo energético dos dois tipos de secadores.

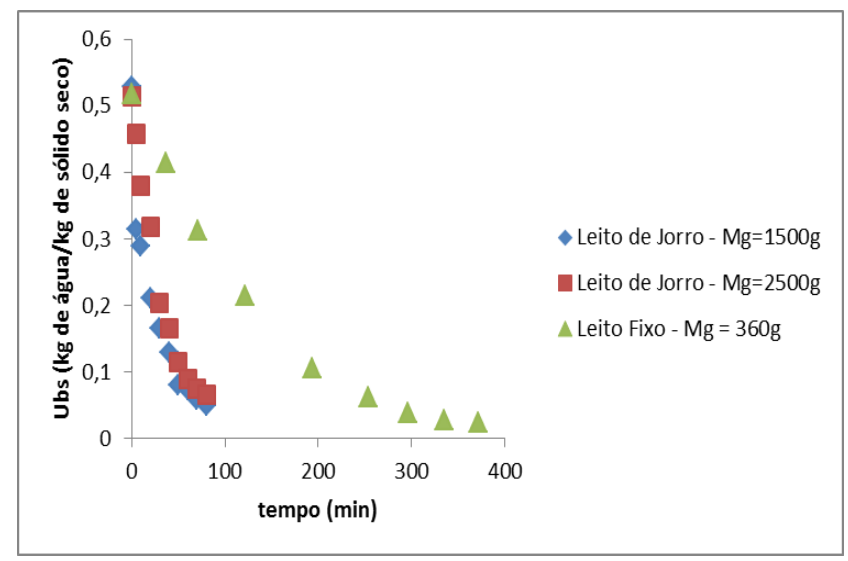

Figura 1 - Curvas de secagem dos grãos de girassol em leito de jorro e em leito fixo $-70{ }^{\circ} \mathrm{C}$ 


\section{LCOBEQ}

19 a 22 de outubro de 2014

Florianópolis/SC

Na Tabela 2, são exibidos os dados relativos à umidade e à atividade de água dos grãos, atingidas ao final de cada experimento e determinadas de acordo com a metodologia apresentada neste trabalho.

Tabela 2 - Atividades de água e umidades finais dos grãos de girassol

\begin{tabular}{c|c|c|c|c|c}
\hline Equipamento & $\mathrm{T}_{\mathrm{ge}}\left({ }^{\circ} \mathrm{C}\right)$ & $\mathrm{M}_{\mathrm{g}}(\mathrm{g})$ & $\mathrm{a}_{\mathrm{wf}}$ & $\mathrm{U}_{\mathrm{bsf}}(\mathrm{kg} / \mathrm{kg})$ & $\begin{array}{c}\text { Tempo de } \\
\text { secagem }(\mathrm{min})\end{array}$ \\
\hline Leito de Jorro & 70 & 1500 & 0,457 & 0,0499 & 80 \\
\hline Leito de Jorro & 70 & 2500 & 0,572 & 0,0659 & 80 \\
\hline Leito Fixo & 70 & 360 & 0,121 & 0,0230 & 372 \\
\hline
\end{tabular}

Conforme os resultados, ao final da secagem a atividade de água e a umidade dos grãos secados na estufa foram mais baixos do que no leito de jorro, todavia se deve destacar o longo tempo de secagem na estufa, conforme já discutido anteriormente. Evidencia-se que o a faixa de umidade recomendada para armazenamento de grãos sem comprometimento da qualidade e capacidade germinativa está entre 3 e 7\%. A umidade dos grãos processados no leito de jorro encontra-se nesta faixa. Em relação à atividade de água, níveis muito baixos como os observados nos grãos processados na estufa, não são recomendados para produtos com elevados teores de gordura, como o girassol.

De acordo a metodologia, aos dados experimentais de secagem dos grãos no leito de jorro e na estufa, foram aplicados os modelos de FICK, considerando 5 termos da série e o modelo de PAGE. Para o modelo de FICK não foram considerados os dados iniciais da umidade, uma vez que a fase inicial da secagem pode ter ocorrido com influência importante das resistências externas. Para determinação dos parâmetros dos modelos, utilizou-se o software STATISTICA 7.0. Os parâmetros obtidos para cada modelo ajustado com respectivos coeficientes de correlação são apresentados na Tabela 3. O bom ajuste do modelo de FICK aos dados experimentais permitiu a determinação da difusividade dos grãos.

Tabela 3 - Modelos ajustados aos dados de secagem dos grãos de girassol

\begin{tabular}{c|c|c|c|c|c|c|c}
\hline \multicolumn{2}{c|}{ Condições Operacionais } & \multicolumn{3}{c|}{ Modelo de Fick } & \multicolumn{3}{c}{ Modelo de Page } \\
\hline Leito & $\mathrm{M}_{\mathrm{g}}(\mathrm{g})$ & $\mathrm{a}$ & $\mathrm{D}_{\text {eff }}\left(\mathrm{m}^{2} / \mathrm{s}\right)$ & $\mathrm{R}^{2}$ & $\mathrm{k}\left(\mathrm{min}^{-1}\right)$ & $\mathrm{n}$ & $\mathrm{R}^{2}$ \\
\hline Jorro & 1500 & 0,79 & $6,65.10^{-10}$ & 0,991 & 0,16 & 0,65 & 0,994 \\
\hline Jorro & 2500 & 0,91 & $4,91.10^{-10}$ & 0,989 & 0,022 & 1,11 & 0,998 \\
\hline Fixo & 360 & 1,04 & $59,9.10^{-10}$ & 0,989 & 0,0024 & 1,26 & 0,999 \\
\hline
\end{tabular}

Como se observa na tabela 3 tanto o modelo de FICK quanto o de PAGE se ajustaram muito bem aos dados experimentais da razão de umidade em função do tempo, com coeficientes de correlação superiores a $99 \%$. No cálculo da difusividade foi considerada a meia espessura média dos grãos para o leito de jorro e para o leito fixo a meia espessura da camada de sementes. Devido a este motivo, para os grãos processados na estufa a difusividade é maior, visto que se trata da difusividade efetiva do leito, pois envolve a mistura de sementes e ar nos interstícios do leito. Para o jorro a difusividade é a dos grãos. Conforme esperado, o parâmetro k da equação de Page, que se correlaciona 
com uma taxa média de secagem por unidade de massa seca, é bem mais elevado para o leito de jorro. As curvas experimentais e preditas pelos modelos para a razão de umidade em função do tempo são ilustradas nas Figuras 2. Percebe-se que os dados preditos pelos modelos reproduzem bem os valores experimentais.

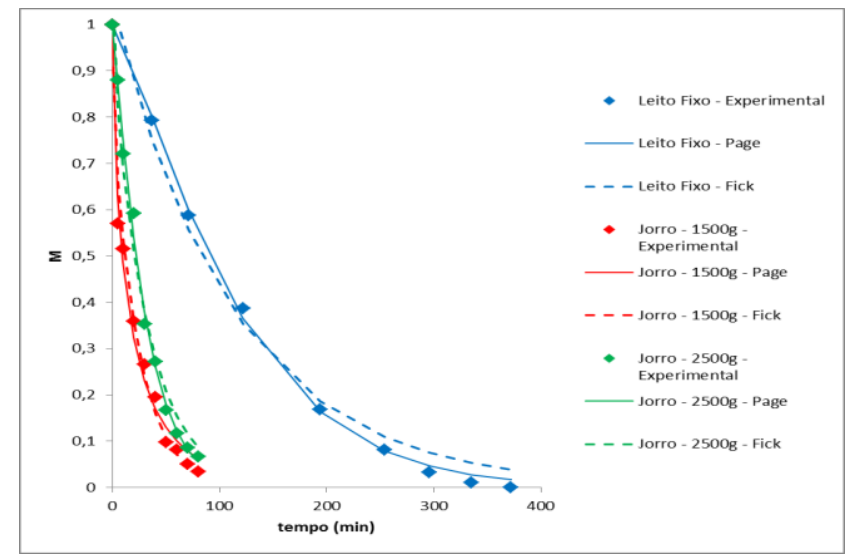

Figura 2 - Curvas da razão de umidade em função do tempo - Dados experimentais e preditos pelos modelos de FICK e PAGE para os leitos de jorro e fixo a $70{ }^{\circ} \mathrm{C}$

Os dados de atividade de água foram obtidos na temperatura do ambiente do laboratório (25 ${ }^{\circ} \mathrm{C}$ ), e assim, todos os dados de equilíbrio correspondem à isoterma a $25{ }^{\circ} \mathrm{C}$. Pode-se, entretanto, avaliar os efeitos da carga processada no leito de jorro ou do tipo de secagem no comportamento das curvas, representadas pela umidade em base seca dos grãos em função da atividade de água. Na Figura 3, são exibidas as curvas de equilíbrio higroscópico para os grãos submetidos à secagem no leito de jorro e no leito fixo.

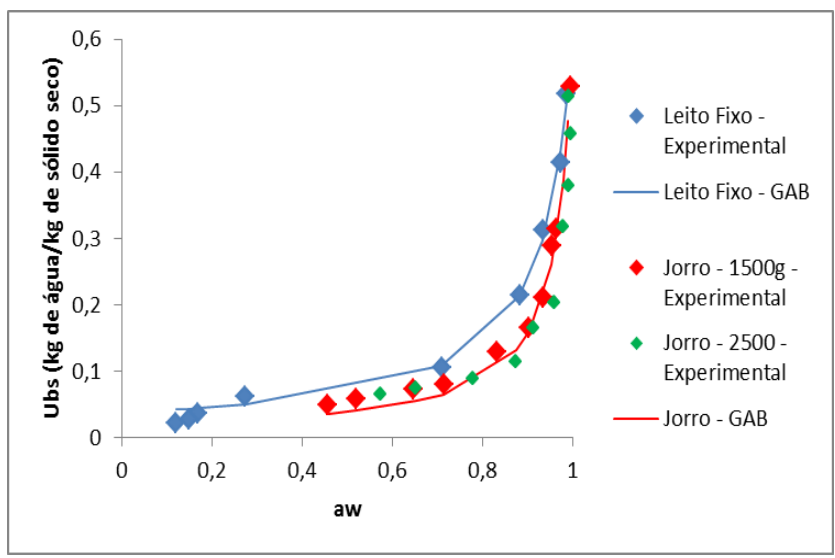

Figura 3 - Curvas de equilíbrio higroscópico a $25^{\circ} \mathrm{C}$ dos grãos de girassol secos em leito de jorro e na estufa para $\mathrm{T}=70^{\circ} \mathrm{C}$. Dados experimentais e preditos pelo Modelo de GAB 
Conforme se observa na Figura 3, para o leito de jorro, independentemente da carga processada os pontos se alinham numa curva única, todavia os grãos secos na estufa apresentam certo desvio no comportamento higroscópico. Assim, aos dados experimentais obtidos nos dois equipamentos, foram ajustados o modelo de GAB para representar o equilíbrio higroscópico dos grãos na temperatura de $25^{\circ} \mathrm{C}$. Na Figura 3 também são apresentadas as curvas ajustadas conforme o modelo. Na Tabela 4 são exibidos os parâmetros do modelo para os dois conjuntos de dados e os respectivos coeficientes de correlação.

Tabela 4 - Parâmetros do modelo de GAB para as condições de operação

\begin{tabular}{c|c|c|c|c|c}
\hline \multicolumn{2}{c|}{ Condições Operacionais } & \multicolumn{4}{|c}{$\mathrm{GAB}$} \\
\hline Leito & $\mathrm{T}\left({ }^{\circ} \mathrm{C}\right)$ & $\mathrm{X}_{\mathrm{m}}$ & $\mathrm{C}_{\mathrm{g}}$ & $\mathrm{K}$ & $\mathrm{R}^{2}$ \\
\hline Jorro & 70 & 0,020 & 130 & 0,968 & 0,980 \\
\hline Fixo & 70 & 0,0503 & 5,49 & 0,91 & 0,993 \\
\hline
\end{tabular}

Verifica-se o bom ajuste do modelo de GAB aos dados experimentais com coeficientes de correlação superiores a 98\%. Percebe-se, também, que os parâmetros da equação ajustada separadamente aos dados obtidos no jorro, com destaque para o $\mathrm{C}_{\mathrm{g}}$ e a umidade na monocamada $\left(\mathrm{X}_{\mathrm{m}}\right)$, diferem dos parâmetros do modelo ajustado aos dados de equilíbrio higroscópico dos grãos secos na estufa. A diferença de higroscopicidade pode ser explicada pelas diferentes condições dos processos de secagem em estudo. Em geral, estas condições podem modificar a estrutura interna do material, mudando assim a área específica e porosidade, que por sua vez, influenciam a umidade de monocamada e podem afetar a afinidade dos sítios ativos pela água, alterando as energias envolvidas.

\section{CONCLUSÃO}

Diante dos resultados apresentados, pode-se avaliar que a secagem dos grãos in natura de girassol no leito de jorro apresentou um ótimo desempenho, quando comparado com a secagem em camada fina na estufa com circulação de ar. Umidades compatíveis com os valores recomendados para manutenção da qualidade fisiológica das sementes foram atingidas em tempos de processamento muito curtos. Os modelos de Fick e Page se ajustaram muito bem aos dados de secagem obtidos tanto no jorro como na estufa, podendo ser utilizados para fins preditivos na faixa de condições experimentais em que foram conduzidos os experimentos. Foram observadas diferenças no comportamento higroscópico dos grãos, o que demonstra que ocorreram mudanças na estrutura interna do material devido aos diferentes processos de secagem a que foram submetidos. Apesar da maior eficiência na secagem dos grãos no leito de jorro, observada pelo curto tempo de processamento para maiores cargas de grãos, necessário se faz realizar os balanços de energia para cálculo do consumo energético deste processo, avaliando-se a viabilidade técnica e econômica do mesmo. 


\section{AGRADECIMENTOS}

Os autores agradecem ao Instituto Federal de Educação, Ciência e Tecnologia do Rio Grande do Norte (IFRN, Campus Apodi), à Universidade Federal do Rio Grande do Norte e ao Programa de Formação de Recurso Humanos da Petrobras (PFRH) pelo incentivo e apoio financeiro.

\section{NOMENCLATURA}

\begin{tabular}{|c|c|c|c|}
\hline $\mathrm{a}$ & parâmetro da equação de $\operatorname{FICK}\left(8 / \pi^{2}\right)$ & $\rho_{\mathrm{p}}$ & densidade da partícula $\left(\mathrm{g} / \mathrm{cm}^{3}\right)$ \\
\hline$a_{w}$ & atividade de água & $\sigma$ & desvios \\
\hline$a_{w f}$ & atividade de água final & $\mathrm{R}^{2}$ & coeficiente de correlação \\
\hline $\mathrm{C}_{\mathrm{g}}$ & parâmetro da equação de GAB & $\mathrm{T}$ & temperatura $\left({ }^{\circ} \mathrm{C}\right.$ ou $\left.\mathrm{K}\right)$ \\
\hline $\mathrm{D}_{\text {eff }}$ & difusividade $\left(\mathrm{m}^{2} / \mathrm{s}\right)$ & $\mathrm{T}_{\mathrm{ge}}$ & temperatura do gás na entrada \\
\hline$\Phi$ & esfericidade da partícula & $\mathrm{t}$ & tempo (s ou min) \\
\hline $\mathrm{j}$ & meia espessura do material (m) & $\mathrm{U}_{\mathrm{bs}}$ & umidade de base seca $(\mathrm{kg} / \mathrm{kg})$ \\
\hline $\mathrm{K}$ & parâmetro da equação de GAB & $\mathrm{U}_{\text {beq }}$ & umidade de equilíbrio $(\mathrm{kg} / \mathrm{kg})$ \\
\hline $\mathrm{k}$ & parâmetro da equação de PAGE $\left(\mathrm{min}^{-1}\right)$ & $\mathrm{U}_{\mathrm{bsi}}$ & umidade inicial (kg/kg) \\
\hline M & razão de umidade & $\mathrm{U}_{\mathrm{bsf}}$ & umidade final $(\mathrm{kg} / \mathrm{kg})$ \\
\hline $\mathrm{M}_{\mathrm{g}}$ & massa do leito (g) (carga de grãos) & $X_{m}$ & umidade na monocamada (GAB) \\
\hline
\end{tabular}

\section{REFERÊNCIAS}

EPSTEIN, N. GRACE, J. R. Spouted Bed, New York, Academic Press, 2011. 364 p.

EVANGELISTA NETO, A. A. Secagem de grãos de girassol em leito fixo e em leito de jorro. $113 \mathrm{f}$. Dissertação (Mestrado em Engenharia Química), PPGEQ/UFRN, Natal, 2013.

GINER, S. A.; GELY, M. C. Sorptional parameters of sunflower seeds of use in drying and storage stability studies. Biosystems Engineering, 92 (2), p. 217-227, 2005;

PESAGRO - Empresa de Pesquisa Agropecuária do Rio de Janeiro, disponível em, http://www.pesagro.rj.gov.br/downloads/maisnoticia_jul07.pdf, consultado em 15/07/2007.

RANGANNA, B.; KAMMAR, C.; PRASAD, S. R.; RAGHAVAN, G. S. V. Drying of Oil seeds for seed production. IN: DRYING 2002 - PROCEEDINGS OF THE 13TH INTERNATIONAL DRYING SYMPOSIUM, Beijing, China, vol. B, p. 1209-1217, 2002.

SANTOS, C. J. R. Secagem de sementes de girassol via radiação infravermelho e convecção forçada de ar aquecido. Dissertação (Mestrado em Engenharia de Processos) - Universidade Tiradentes UNIT, Aracajú-SE, 2009. 